\title{
Correction to: Removal of a urinary catheter before discontinuation of epidural analgesia is associated with an increased risk of postoperative urinary retention and hospital episode costs in patients undergoing surgical correction for adolescent idiopathic scoliosis
}

Assem A. Sultan ${ }^{1} \cdot$ Ryan J. Berger ${ }^{1}$. William A. Cantrell ${ }^{1,2} \cdot$ Linsen T. Samuel $^{1} \cdot$ Erin Ohliger $^{1} \cdot$ Joshua Golubovsky $^{2}$. Salam Bachour ${ }^{2}$. Selena Pasadyn ${ }^{2}$. Jaret M. Karnuta ${ }^{2} \cdot$ Pierre Tamer $^{2} \cdot$ Phuc Le $^{3}$. Thomas E. Kuivila ${ }^{1}$. David P. Gurd ${ }^{1}$. Ryan C. Goodwin ${ }^{1}$

Published online: 2 March 2020

(c) Scoliosis Research Society 2020

\section{Correction to: Spine Deformity}

https://doi.org/10.1007/s43390-020-00039-y
Publisher's Note Springer Nature remains neutral with regard to jurisdictional claims in published maps and institutional affiliations.

The original version of this article unfortunately contained a mistake. The spelling of Dr. Erin Ohliger's name was incorrect. The correct name is Erin Ohliger.

The original article has been corrected.

The original article can be found online at https://doi.org/10.1007/ s43390-020-00039-y.

Assem A. Sultan

assem.sultan@gmail.com; sultana@ccf.org

1 Department of Orthopaedic Surgery, Cleveland Clinic, 9500 Euclid Avenue, Cleveland, OH 44195, USA

2 Cleveland Clinic Lerner College of Medicine, 9500 Euclid Avenue NA21, Cleveland, OH 44195, USA

3 Center for Value-Based Care Research, Cleveland Clinic, 9500 Euclid Avenue, Cleveland, OH 44195, USA 